\title{
ChINA Y SU IMPACTO EN NUESTRA ECONOMíA
}

\author{
Zelma Wong Torres \\ Luisa E. Salcedo Guzmán \\ Docentes-Facultad de Ciencias Contables
}

"China es un gigante dormido, cuando despierte, hará temblar al mundo"

NAPOLEÓN

\begin{abstract}
RESUMEN
Hoy se sabe que China es la nueva potencia mundial debido a su gran crecimiento económico cuya tasa promedio anual es del $9 \%$ desde 1978, convirtiéndose para nuestro país en un gran socio comercial, pues es el tercer destino de nuestras exportaciones, conformando de esta manera el $20 \%$ del total de muestras exportaciones; sin embargo nosotros para China no alcanzamos el $1 \%$ en importaciones. Siendo China un gran mercado, ¿por qué razón no llegamos al $1 \%$ de sus importaciones? Una de las principales razones podría deberse a la falta de capital, de tecnología, de capacidad y calidad exportadora, entre otras razones.

China es realmente un gigante que busca consolidar su crecımento a nivel mundial; en cuanto a América atina, China está dispuesta a invertir en países tales como: Argentina, Chile, Brasil y Perú, mediante tratados de libre comercio. En este artículo nos hemos propuesto exponer las ventajas y desventajas que implica el surgimiento de la economía china en nuestro país.
\end{abstract}

Palabras clave: China, calidad de exportación, Inserción en la economía global.

\section{INTRODUCCIÓN}

\section{LA REPÚBLICA POPULAR CHINA}

LaRepúblicaPopular Chinafue fundada en el año 1949, luego del triunfo de Mao Zedong (Mao Tse Tung) sobre Chiang Kai Shek, y reconocida por la Asamblea General de la Naciones Unidas a fines de la década del 60 .

El cambio en la República Popular China empezó hace 27 años con Deng Xiaoping, reconocidocomoel "hombre delaño" enelaño 1986, quien dió inicio a las reformas económi-

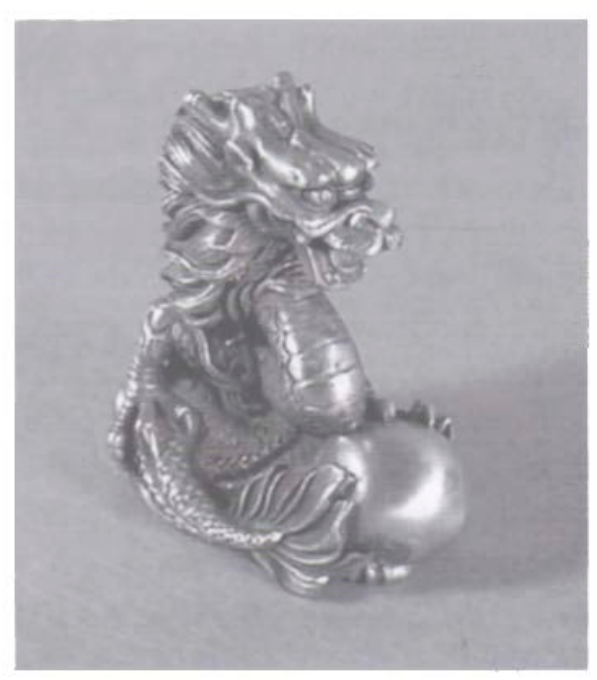


cas que posibilitaron la progresiva apertura de China al mundo. Su célebre aforismo «No importa si el gato es negro o blanco, mientras cace ratones, es un buen gato».

\section{Estrategia de China}

a) Generarun sistemadepropiedad privada.

b) Insertarse económicamente al mundo.

c) Elevar el nivel económico de su población: con esfuerzo todos pueden ser ricos y prósperos.

d) Desarrollar primero la zona de Costa y el Este de China para luego seguir con el Oeste.

e) Desarrollar un modelo socialista de mercado propio de China.

f) Respetar la propiedad privada y los Derechos Humanos.

\section{Problemas del Gigante}

Hay que tener presente que China enfrenta tres grandes problemas: 1) El elevado número de empresas públicas no rentables que deben dinero a los bancos; 2) la delicada situación del sistema financiero; 3) la desenfrenada construcción residencial impulsada por Beijing y Shangai; mediante creditos hipotecarios.

\section{Aspectos Político-Económicos}

Se establecieron relaciones diplomáticas entre Perú y China mediante convenio conjunto el 02 de noviembre de 1971, suscrito en Ottawa, Canadá, en donde el Perúreconocióala República PopularChina como único representante legal del pueblo chino. Ambos países establecieron embajadas residentes en marzo de 1972, Perú cuenta con un Consulado General en Hong Kong y en mayo del 2002 estableció un Consulado General en Shangai.
En 1978, China inició una serie reformas cuyos resultados se aprecian en crecımiento económico de $9 \%$ anual en años 1980-2004. Según el Banco Mundi. la pobreza se redujo de $64.6 \%$, en 1981 $23,5 \%$, en 1986 y $12.5 \%$ en el 2001 , d el 2004 la economía china ha ido en asce China ha respetado los principi económicos básicos y los ha ido adaptando a su realidad.

El 20 octubre del año 2001, ei Presidente del Perú, don Alejandro Toledo. sostuvo conversaciones en Shangai con ej entonces presidente Jian Zemin, durante la IX Cumbre de Líderes APEC. Lo mismo sucedió durante la Cumbre Informal de líderes APEC en México en el año 2002 Esta mismacumbrefue el lugar de encuentro entre el presidente Toledo con $\mathrm{Hu}$ Jintao celebrada en Bangkook en el 2003 y en Santiago de Chile en el 2004.

\section{En torno a la inversión}

Hu Jintao manifestó que China ha pasado de una situación de supervivencia a otra de modesta prosperidad. Actualmente China es la sexta potencia económica mundial, para el 2020 llegaría a ser la principal potencia económica y fuente de turismo en el mundo con un estimado de 100 mullones de viajeros. El estado peruano busca aprovechar la adaptación de un memorandum de entendimiento en materia de turısmo, suscrito entre Perú y China con Zeng Quinghong.

El crecimiento económico de China, está afectando a los países de Sudamérica Centroamérica y México, especialmente en el rubro de manufactura. La oferta de productos chinos plantea retos al mundo, $y$ hay que reconocer que los investigadores se equivocaron en sus predicciones 
económicas. China se ha convertido para muchos en una amenaza, para otros en una oportunidad, Perú debe incentivar a sus más connotados investigadores universitarios para afrontar este reto con inteligencia.

Teniendo presente que, América Latina produce muchos bienes que $C$ hina requiere para su economía, es conveniente para países como el nuestro, exportadores de materia prima, tener en cuenta que China es un importante socio comercial; en los últimos dos años se han registrado exportaciones de productos notradicionales, tales como uña de gato, cuero, uvas, entre otros; siendo una oportunidad para el sector agrario (horticultores, fruticultores); sin embargo, la manufactura China es bastante competitiva, constituyéndose en una amenaza para el Perú con respecto a sus exportaciones textileras y otros productos manufacturados, debido a factores tales como el salario y el flujo laboral (grandes desventajas para nuestro país). Con el propósito de proteger a este sector, en el 2004, el gobierno del Estado Peruano, mediante Decreto Supremo incluyó como productos sensibles a las subpartidas arancelarias referidas a las confecciones.

\section{Perú y las exportaciones}

Perú invierte muy poco en innovación e investigación para el desarrollo de nuevas tecnologías, en el sistema productivo, que mejorarían la calidad e incrementarían la competitividad de nuestros productos frente a otros países. Lamentablemente no se da un vínculo de compromiso entre las empresas y las universidades mediante centros deinvestigación, implementación de laboratorios, etc.

Se debe generar un proceso dinámico de desarrollo que ayude a resolver los problemas de pobreza, inequidad e ineficiencia macroeconómica; debemos incrementar la inversión internacional, lo que conllevaría al acceso de mercados y mejoras de calidad en la participación interna, aprovechar de manera estratégica las alternativas de inserción internacional mediante tratados de libre comercio e integración multilateral. El mejoramientode los productos, la firma de acuerdos preferenciales, definitivamente mejorarían nuestras exportaciones con el "gigante".

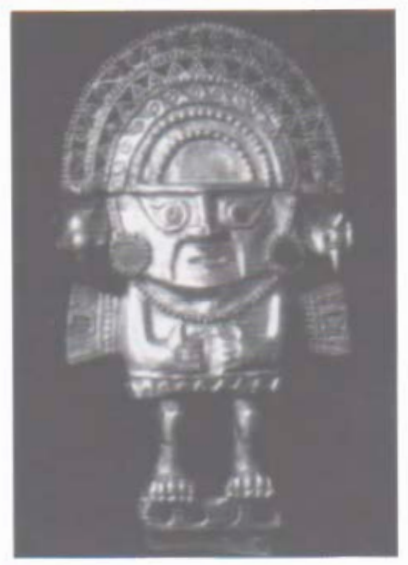

Debemos ver el auge de China como una gran oportunidad para crear las condiciones necesarias y atraer sus inversiones; es necesario desarrollar tecnologíaseinnovación alrededor de las necesidades de China, que nos permitan exportar materia prima con nuestros serviciosdeconocimiento; debemos diversificar el destino de nuestros productos, conocer el mapa exportador y aprovechar las vinculaciones para dinamizar el comercio.

A nuestro entender, Perú debe considerar los siguientes aspectos para su desarrollo e inserción en la economía global:

\section{Competitividad}

Hacer reformas macroeconómicas: atención a la inversión, calidad e innovación en los productos liberalización de los mercados de factores (capital y trabajo), 
inversión en infraestructura, etc. En nuestro país debemos pensar y actuar en competencia y voluntad de hacer.

Se debe reforzar y mejorar los vínculos entre la empresa y la universidad, los cuales son muy débiles para la oferta productiva. Debe formularse nuevas leyes que coadyuven a incentivar la inversión y desarrollo que comprenda las siguientes áreas:

1 Recursos naturalescomo: la pesca, la tala.

2 Incentivo a los investigadores.

Se propone:

$33 \%$ en incentivos al investigador,

$33 \%$ al lugar de origen, $y$

$34 \%$ a la facultad de la universidad.

3 Se debe establecer mecanismos claros de incentivos a los investigadores sin muchas trabas legales ni burocráticas.

\section{Para lograr con éxito la inserción en el proceso de globalización mundial de- bemos tener en cuenta los siguientes puntos:}

1 El negocio y la inversión: se debe actualizar y/o modificar las leyes que afectan los procesos empresariales tales como: los registros de creación de empresas, liquidación de empresas, transferencias de propiedad, ejecución de contratos, agilidad, seriedad, estabilidad y claridad del marco legal.

2 Oferta productiva de la región: calidad y oportunidad en el proceso productivo, muchos países exigen subir los estándares de calidad para aceptar un producto, en Perú es el $0.11 \%$ del PBI; debe elevarse al $1 \%$ prioritario en la agenda de la región, como mínimo.

3 Inserción: es posible lograrlo en la medida de alcanzar los niveles óptimos en los estándares de calidad a nivel mundial.
4 Competitividad en los costos operativos e infraestructura con los mejores mercados mundiales.

\section{CONCLUSIÓN}

AsícomoChina puedesignificar unagran oportunidad para que Perú mejore su capacidad exportadora y crezca en su economía nacional, estambién una amenaza; pues debido a los bajos salarios y su gran capacidad productiva, resulta ser de gran competencia para nosotros frente a otros países, en especial en la industria textilera. Este aspecto debería comprometer a dicha industria, así como también al sector agrario, con ayuda del Estado peruano a mejorar la capacidad competitiva de los productos que exportamos, así como propender a formar alianzas con empresarios de otros países. Es evidente que el camino no es fácil, pero teniendo presente que en la actualidad llevar nuestros productos a Chinaes menoscostoso que llevarlos a Pucallpa, se aprecia que hay muchos factores internos que deben ser modificados, para hacer posible el mejoramiento y la inserción de nuestro país a la era actual de la globalización.

\section{REFERENCIAS}

1. Asociación Peruano China, Boletín InformatuoN. ${ }^{\circ} 23$. Setiembre 2004-11-02.

2. Sagastegui, Francisco y Daucelin Jenn. Los estudios futuros en América Latina. Tendencias y ecomomías, Perú, 1999.

3. Mc Lauchlan Arregui, Patricia; Acosta, Laura. Perú 2010: El futuronoescomoantes. Perú, 1988.

4. Pampollón Olmedo, Rafael. "China, país estrelladel sigloXXT”. En:PuntodeEquilibrio, año 14. N. $^{\circ} 88$, julio 2005 , p. $22-23$. 